\title{
On the semantics of number morphology
}

\author{
Gregory Scontras ${ }^{1}$
}

Accepted: 12 November 2021 / Published online: 19 February 2022

(C) The Author(s) 2022

\begin{abstract}
This paper develops a semantic account of morphological number marking, specifically in the presence of numerals. In addition to accounting for number marking on basic nouns like book in English, the account handles variation in patterns of number marking along two dimensions: cross-linguistically, between languages that either necessitate or prohibit singular morphology in the presence of numerals greater than 'one'; and within one and the same language on the various nominal elements in English. Building off the presuppositional approach to morphological number from Sauerland (Proc SALT 13:258-275, 2003), the proposed semantics accounts for both sorts of variation by assuming flexibility in the selection of the measure relevant to the one-ness presupposition of the morphological singular form.
\end{abstract}

Keywords Number marking · Numerals · Measure terms · Cross-linguistic variation

\section{Introduction}

Speakers of number-marking languages decide between singular and plural forms of nouns as they embed them in larger linguistic contexts. In English, book is felt to mean something different from books, and the choice between these forms is regular and well-defined. If we are talking about a single book, we must use the singular form of the noun; when we are talking about more than one book, we use the plural. While this characterization of grammatical number in terms of one vs. more-thanone is not without its problems (we return to this point in Sect. 2.1 below), for now

Gregory Scontras

g.scontras@uci.edu;

http://langsci.uci.edu/scontras

1 Department of Language Science, School of Social Sciences, University of California, Irvine,

3151 Social Sciences Plaza, CA 92697 Irvine, USA 
the rough identification of singular morphology with singular reference and plural morphology with plural reference gives us a point from which to begin investigating the topic at hand: the impact that numerals have on the determination of grammatical number.

In English, the numeral one requires that the noun it appears with bear singular morphology, thus one book and not one books. For numerals greater than one, plural morphology is required: two books and not two book. We can describe this pattern using our characterization of grammatical number above: with one, we are talking about a single thing and so we require the singular form; with greater numerals, we are talking about more than one thing, thus the plural form must be used. The problem lies in explaining how these facts arise. What aspect of the linguistic form is responsible for the choice of grammatical number, and at what level of grammar does it operate?

Suppose that the determination of grammatical number were a wholly syntactic process driven by grammatical features of the modificational elements that then agree with features on modified nouns (e.g., Krifka, 1989). Such a system would posit a SINGULAR feature on the numeral one and a PLURAL feature on all other numerals, at least in English. When composing with a noun, the number feature of the numeral would value the number feature of the noun and determine its morphological form. Note that this feature distribution, one+singular and notone +PLURAL, captures the facts of English, but the system being considered admits a great deal of variation beyond the English pattern. Without ad hoc stipulations concerning the distribution of these features, a numeral could possess any number feature and so we should expect to find languages with unintuitive-and unattested-patterns of number marking. For example, how would we block a language from attributing the PLURAL feature to one and the SINGULAR feature to all other numerals? In other words, how do we rule out languages in which nouns agree with one in the plural and numerals other than one in the singular? Note that the language under consideration differs from English in that singular and plural morphology behave as expected in the absence of numerals, but with numerals we witness the diverging pattern. The problem with a purely syntactic, or featural approach is that grammatical number bears only an indirect relationship to the meaning of the elements indexed with it, and so we lack a principled way of constraining the patterns that can be generated. Such an approach also leaves unanswered the question of how number morphology on nouns gets determined in the absence of modificational elements that would carry number features.

The solution lies in the semantics. The current paper offers an account of grammatical number in the presence of numerals that attributes the distinction between singular and plural forms to an interaction between the meaning of numerals and the semantics of the nominal element with which they compose. ${ }^{1}$ In addition to accounting for number morphology on basic nouns like book in English, the approach extends to cover data from two seemingly disparate domains: (i) number marking on measure terms like kilo, which is determined by the numeral co-

\footnotetext{
1 See Scontras (2013a, 2013b, 2014) for earlier versions of this proposal. For a different evolution of the ideas that incorporates the analysis of number features from Harbour (2014), see Martí (2020b).
} 
occurring with these terms: one kilo of apples vs. two kilos of apples; and (ii) crosslinguistic variation in patterns of number marking: numerals other than 'one' obligatorily combining with plural-marked nouns (e.g., English), all numerals obligatorily combining with singular (i.e., unmarked) nouns (e.g., Turkish, Hungarian), and numerals optionally combining with either singular or plural nouns (e.g., Western Armenian).

What results is a semantic program centered around a designated functional projection, \#P, from which morphological number features originate (cf. Sauerland, 2003 , a.o.). The head of \#P, either SG or PL, is an operator that establishes conditions on the denotation of the resulting nominal: SG checks for singularity of the predicate, and PL applies when singularity is not satisfied. In other words, the morphological singular form requires that the nominal indexed with it reference only things that number 1 . Variation in the way that singularity is checked captures the cross-linguistic diversity in patterns of number marking that we encounter. This variation also accounts for number marking within the domain of measure terms. Before beginning to develop this system, we must consider in more detail the assumptions at its foundation, together with the data to be explained. This is the topic of the next section.

\section{Toward a proposal}

For a noun to be semantically singular, let us begin by assuming that it must denote a set of atoms. What about semantic plurality? If singularity is tied with atoms, then a plural noun could denote sums of atoms (Link, 1983). We thus carve up our domain of individuals as in Fig. 1, where 'atoms' is tantamount to singulars, and 'sums' is tantamount to pluralities.

The singular/plural distinction as realized in Fig. 1 makes more precise our intuitions on the contrast between nouns like book vs. books: the former refers to a set of book atoms (e.g., $\{a, b, c\})$ while the latter refers to a set of book sums $(\{a+b, a+c, b+c$, $a+b+c\}$; but see Sauerland et al. (2005), for a finer grained notion of this contrast; we return to this point below). When someone uses singular book, he is talking about single individuals; when he uses books, he is talking about pluralities of books.

Nominal morphology is in some way sensitive to the distinction between singularities (atoms) and pluralities (sums); our task is to determine what this way is. Here are the bones of the idea: if a noun's denotation contains individuals formed

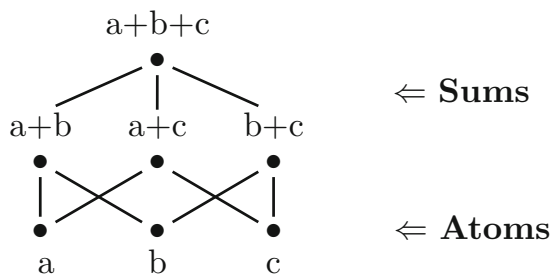

Fig. 1 The plural domain 
by the sum operation + , then that noun appears with plural morphology. Thus, when talking about pluralities, we use the plural form of the relevant noun. When referencing atomic individuals, we use the singular form. What follows is a proposal linking semantic number (i.e., the distinction between atoms and sums) with morphological number (i.e., the form a noun takes).

\subsection{Theoretical foundations}

We begin by reviewing Sauerland's (2003) proposal for linking semantic number with morphological number. Sauerland develops an extensional account of the semantics of morphological number: when a DP like the book references a single atomic individual, singular morphology surfaces on the nominal and effects singular agreement with other elements in the sentence. When a DP does not reference a single individual, plural morphology and agreement result. The job of checking the numerosity of nominal referents falls to a syntactic head that projects above the determiner; Sauerland terms this element the " $\phi$ " head. The structure in (1) results.

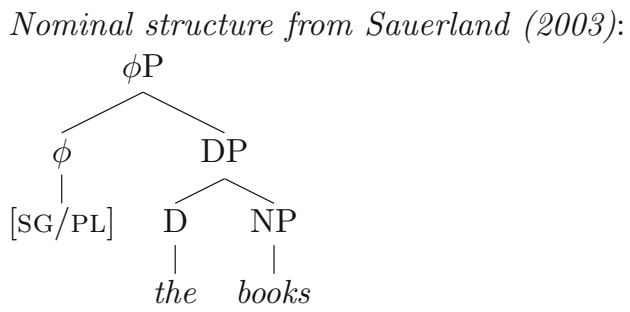

The $\phi$ heads host number features, which control agreement. The sG head determines the morphological singular form, and the PL head determines the morphological plural. One process establishes agreement within the nominal between nouns, adjectives, determiners, and the $\phi$ head; another process establishes agreement between the $\phi \mathrm{P}$ in subject position and the finite verb.

There are two crucial aspects to Sauerland's proposal: (i) the semantic contribution of number morphology is separate from the semantic distinction between atomic individuals and pluralities, and (ii) only the number features in $\phi$ are semantically interpreted; moreover, these features are interpreted as presuppositions. Sauerland endows the $\phi$ heads with the semantics in (2); they are identity functions that take an individual and return that individual if certain conditions are met. $^{2}$

$$
\begin{aligned}
& \phi \text { heads from Sauerland (2003): } \\
& \text { a. } \llbracket \mathrm{SG} \rrbracket=\lambda \mathrm{x}: \neg \exists \mathrm{a}\left[\mathrm{AT}_{w}(\mathrm{a}) \wedge \mathrm{a}<\mathrm{x}\right] . \mathrm{x} \\
& \text { b. } \llbracket \mathrm{PL} \rrbracket=\lambda \mathrm{x} . \mathrm{x}
\end{aligned}
$$

\footnotetext{
${ }^{2}$ The denotations in (2) translate Sauerland's notation into one that matches those of the current paper: $\mathrm{AT}_{w}(\mathrm{x})$ checks the atomicity of $\mathrm{x} ; \mathrm{y}<\mathrm{x}$ states that $\mathrm{y}$ is a proper mereological part of $\mathrm{x}$.
} 
Singular SG encodes the presupposition that the nominal referent has no atomic proper part, which limits possible referents to atoms or portions of substance (e.g., the water). Plural PL makes no demands beyond requiring that its sister denote a (plural) individual; the principle of Maximize Presupposition (Heim, 1991) mandates that SG gets used whenever possible. This move-an empty semantics for the plural-allows for mixed reference in cases like the following (from Sauerland's example (33); see also example (4)):

a. Every boy should invite his sister.

b. Every boy should invite his sisters.

In (3a), singular sister is acceptable just in case each boy has only one sister. However, in (3b), plural sisters is compatible with plural or singular reference. The following examples illustrate the same point; in each case, the plural form is compatible with singular reference.

(4) a. There are no dogs outside.

b. If you have children, bring them to the party.

c. Every student with unexcused absences can expect an F in the course.

The weak semantics of PL makes this inclusive interpretation possible. Moreover, semantic plurality - that is, whatever creates sums of individuals out of atoms-gets handled separately from $\phi$, presumably by a Link-style sum-closure operator, *.

\subsection{More data}

There are at least two reasons to doubt the hierarchical placement and referentchecking semantics of Sauerland's $\phi \mathrm{P}$. First, nominals express morphological number in the absence of a determiner, as in NP conjunction or compounds (e.g., the boy and girl who were at the party...). More importantly for our purposes, if the role of the morphological singular SG is always to check the atomicity of the referent, we have no hope of allowing singular-marked nominals to refer to a plural individual in cases like one kilo of apples, where multiple apples are referenced. Similarly, in languages where all numerals appear with singular morphology, there would be no way to satisfy atomicity with the plurality referenced by 'two book'. What follows is a quick overview of the expanded set of data for which the semantics of number morphology must account.

\subsubsection{Measure terms}

So far we have been considering number marking on basic nouns like book. These nouns may be viewed as one-place predicates, denoting sets of individuals holding the relevant property. We defined semantic plurality for these predicates in terms of the cardinality of the members of their denotations: if a predicate refers to a set of atoms (i.e., individuals with cardinality 1), it is semantically singular; if the 
predicate is closed under sum-formation, it is semantically plural. But what happens when we have nouns that do not refer to individuals, atomic or otherwise, that still behave regularly with respect to number marking? Of interest are the italicized words in (5).

$$
\begin{aligned}
& \text { a. That meat weighs two kilos. } \\
& \text { b. I ate two kilos of meat. }
\end{aligned}
$$

We must first convince ourselves that measure terms like kilo are nouns, or at least nominal to the extent that they should be handled by the same system of number marking that determines the morphology of book vs. books. To begin, measure terms display regular singular/plural morphology: kilo vs. kilos. Further, they are free to combine with numerals, and when they do they behave as expected, reserving the morphological singular form for the numeral one: one kilo vs. two kilos. Finally, measure terms are subject to quantifier restrictions: many kilos but not much kilos.

Assuming that we take these facts as evidence that measure terms are nominal elements, what do we make of the semantics of singular vs. plural for them? We started with the schema relating morphological and semantic number in (6), but it is not clear how this schema could apply to measure terms.

$$
\begin{array}{ll}
\text { a. } & \text { atoms } \Rightarrow \mathrm{SG} \\
\text { b. } & \text { sums of atoms } \Rightarrow \mathrm{PL}
\end{array}
$$

The problem is that measure terms do not appear to refer in the way that boy does (for discussion, see, e.g., Parsons, 1970; Scontras, 2021). What kind of atoms are kilos, meters, degrees, etc.? What would it mean to close sets of these supposed atoms under sum formation? I thus take as my starting point the idea that measure terms are nouns that do not refer to individuals, at least not directly.

When it composes with a substance noun and a numeral, a measure term characterizes the set containing elements that measure the appropriate amount and instantiate the substance noun. For now I leave aside the details of the composition between a measure term and the substance noun (though see Scontras, 2021). The result of this composition is the predicate in (7), which denotes a set of apple quantities, each weighing 1 kilo.

$$
\llbracket \text { one kilo of apples }=\lambda \mathrm{x} .{ }^{*} \text { apple }(\mathrm{x}) \wedge \mu_{k g}(\mathrm{x})=1
$$

Suppose we retrieve a single element of the predicate denotation-some apples- to refer to with one kilo of apples. Chances are our referent will be a plurality of apples, which should trigger plural morphology under Sauerland's semantics: the presupposition of the singular is not met by a plurality (i.e., a non-atom). However, what matters to the number morphology of measure terms is not atom-hood, but 
rather the measure specified by the term itself. The choice between one kilo and two kilos does not depend on how many atomic individuals weigh the relevant amount; in one kilo of apples, we possibly (and probably) reference more than a single apple, yet singular morphology surfaces on the measure term. Sauerland's referentchecking semantics appears ill-suited to handle number marking on measure terms.

\subsubsection{Cross-linguistic variation}

Languages vary with respect to their patterns of number marking in the presence of numerals. So far we have considered one type of language, exemplified by English, in which the numeral one co-occurs with singular-marked nouns and all other numerals require plural-marked nouns. Here we consider data from two other types of languages. In the first, all numerals obligatorily combine with singular-marked nouns ('one book', 'two book'; e.g., Turkish or Hungarian; Bale et al., 2011a; Farkas and de Swart, 2010); in the second, numerals optionally combine with either singular- or plural-marked nouns ('one/two book(s)'; e.g., Western Armenian; Bale et al., 2011a). Bale et al. (2011a) offer an account of these facts that treats nominal denotations and numeral semantics as distinct across languages. Farkas and de Swart (2010) derive the patterns within the framework of Optimality Theory. I adopt the null hypothesis that the denotations of nouns and numerals remain constant across number-marking languages, and assume that a standard compositional semantics determines number morphology. Although Sauerland's system meets these challenges, it cannot account for either of these cross-linguistic patterns, as least not in its original formulation.

Turkish possesses a morphological distinction between singular and plural nouns, as evidenced in (8); the morpheme -lar indexes plurality. ${ }^{3}$ The choice of this morphology is regular and well-defined; the singular form is used to reference singular individuals and the plural form references pluralities. So far, tying the oneness presupposition of SG to basic atom-hood can capture these facts, as in the case of English.

$$
\begin{array}{ll}
\text { a. } & \text { çocuk } \\
& \text { boy }(\mathrm{sg}) \\
\text { b. } & \text { çocuk-lar } \\
\text { boy-pl }
\end{array}
$$

Unlike with English, however, in Turkish-like languages all numerals, crucially those greater than 'one', require singular morphology. Concretely, in the presence of a numeral, -lar is prohibited, (9b). In other words, nouns in Turkish are obligatorily singular, at least morphologically so, when they occur with numerals. Despite clear reference to pluralities (i.e., to two boys), the noun çocuk 'boy' in (9a) expresses singular morphology.

\footnotetext{
${ }^{3}$ All cross-linguistic data in this subsection come from Bale et al. (2011a). See Sağ (2018) and Martí (2020b) for arguments that morphologically-singular nouns in Turkish are in fact semantically singular.
} 

a. iki çocuk two boy(sg)
'two boys'
b. *iki çocuk-lar
two boy-pl

A more complex pattern of number marking has been reported for Western Armenian. Like Turkish and English, Western Armenian possesses productive plural morphology: the morpheme -ner indexes plurality.

$$
\begin{array}{ll}
\text { a. } & \text { degha } \\
\text { boy }(\mathrm{sg}) \\
\text { b. } \\
\text { degha-ner } \\
\text { boy-pl }
\end{array}
$$

Western Armenian's pattern of number marking in the presence of numerals represents a hybrid of the English and Turkish systems: nouns either may appear as morphologically singular in the presence of a numeral greater than 'one', as in Turkish, or they may appear as morphologically plural, as in English. ${ }^{4}$

$$
\begin{aligned}
& \text { a. yergu degha } \\
& \text { two boy(sg) } \\
& \text { 'two boys' } \\
& \text { b. yergu degha-ner } \\
& \text { two boy-pl } \\
& \text { 'two boys' }
\end{aligned}
$$

The atom-sensitive system of number marking above predicts neither the Turkish facts in (9) nor the Western Armenian facts in (11): there is no way for a plurality to satisfy the atom-checking presupposition of SG. We need a way to allow singularmarked nominals to receive a plural interpretation, that is, to be semantically plural. Note that this is the same need that we arrived at in the case of English measure terms: singular morphology must sometimes allow for plural reference.

\section{A minimal modification}

Following Sauerland (2003) (see also Sauerland et al., 2005), let us continue to assume that the locus of syntactic number features is a designated functional head. To distinguish the current approach from Sauerland's, I term this element the "\#"

\footnotetext{
${ }^{4}$ This description of morphological number in Western Armenian from Bale et al. (2011a) is likely an idealization; see Sigler (1996) for a fuller discussion of the facts. Keeping in mind that much more work remains to be done to better understand the nuanced interpretations of these nominals, the present goal will be to leave open the option for the proposal to account for the Western Armenian system as it is presented in Bale et al. (2011a).
} 
head. Morphological number marking arises as a result of syntactic agreement with \#. In this system, morphological number is never directly interpreted; the determination of semantic number is a separate but related process. That is, the \# heads do not contribute directly to the semantics of the nominals with which they compose. Instead, the \# head that surfaces depends on the semantics of the nominal with which it composes. The details follow.

We find (minimally) two variants of the \# heads: SG and PL. ${ }^{5}$ Here I depart from Sauerland, who assumes that $\phi$ composes once a nominal references individualsthat is, at the DP layer. Instead, suppose that \# occurs as the sister to a nominal projection, as in (12), and serves as an identity map on the predicate denoted by the nominal with which it composes.

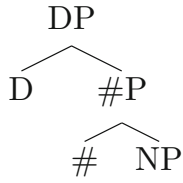

By composing below D, number morphology checks properties of the predicate denoted by NP, rather than the individuals referenced by DP; as we shall see, this move allows greater flexibility in accounting for measure terms and cross-linguistic patterns of number marking. Still, a major contribution of Sauerland's work is the demonstration that SG, and not PL, is semantically marked. ${ }^{6}$ Rather than checking for an atomic referent, the \# head SG carries with it a numerical presupposition for oneness of the property with which it composes, (13a). To satisfy the presupposition of SG, every member of the predicate denotation must measure 1; PL carries no such presupposition, (13b). For now, suppose that the measure $\mu$ relevant to the one-ness presuppotion of SG is basic cardinality: $\mu(\mathrm{x})=\mu_{\text {card }}(\mathrm{x})$. The choice between SG and PL is mediated by Heim's (1991) principle of Maximize Presupposition, which ensures that SG is used whenever its one-ness presupposition is met.

$$
\begin{aligned}
& \text { \# heads: } \\
& \begin{array}{l}
\text { a. } \llbracket \mathrm{SG} \rrbracket=\lambda \mathrm{P}: \forall \mathrm{x} \in \mathrm{P}[\mu(\mathrm{x})=1] . \mathrm{P} \\
\text { b. } \llbracket \mathrm{PL} \rrbracket=\lambda \mathrm{P} . \mathrm{P}
\end{array}
\end{aligned}
$$

At this point, we must draw a clear distinction between morphological number, expressed primarily by $\varnothing$ and $-s$ in English and determined by the functional \# heads SG and PL, and semantic number. Consider a world with three books: $a, b$, and $c$. In its basic form, semantically-singular book denotes a set of atoms, (14a). The star

\footnotetext{
5 Additional \# heads are likely needed to account for dual, trial, paucal, etc., values of grammatical number. See Martí (2020a) for a fuller discussion of both the empirical terrain and a theoretical account extending a variation of the proposal advanced herein to singular-dual-plural systems.

${ }^{6}$ See Sauerland et al. (2005) for a discussion of the facts that lead to this conclusion. For fuller discussion, including potential pitfalls and alternatives to a presuppositional account, see, among others, Spector (2007), Zweig (2009), Ivlieva (2014), Ivlieva and Sudo (2015), Mayr (2015).
} 
operator * (Link, 1983) closes the semantically-singular property, (14a), under sum formation, + , and produces the plural property, (14b).

$$
\begin{array}{ll}
\text { a. } & \llbracket b o o k \rrbracket=\{a, b, c\} \\
\text { b. } & \llbracket{ }^{*} \text { book } \rrbracket=\{a, b, c, a+b, a+c, b+c, a+b+c\}
\end{array}
$$

Suppose that in number-marking languages nouns always express grammatical number. In other words, nouns always appear in the presence of \#. The semantically-singular property in (14a) may compose with SG: every member of $\llbracket$ book》 is atomic and thus has cardinality 1, so the presupposition of SG is satisfied. We thus predict that morphologically-singular nouns refer exclusively to atoms. All of the members of the set characterized by the semantically-singular predicate in (14a) are atomic, and to reference a member of this predicate we use the morphologically-singular book. The semantically-plural property in (14b) does not satisfy the one-ness presupposition of SG in (13a) because there are elements of

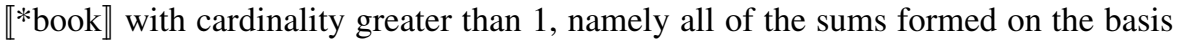
of $*$ (e.g., $a+b, b+c$, etc.). By precluding the combination of semantically-plural properties with SG, we predict that morphologically-singular nouns do not refer to pluralities; if one were to reference pluralities, a semantically-plural property would be required, and so the morphologically-plural form of the corresponding noun would be used. For basic nouns like book, this is a welcome prediction.

Without any presupposition on its use, PL may compose with either of the properties in (14). What blocks PL's combination with semantically-singular properties, (14a), and thus accounts for why morphologically-plural books is not used to refer exclusively to book atoms, is the principle of Maximize Presupposition (Heim, 1991). Compare the strings in (15).

$$
\begin{array}{ll}
\text { a. } & \llbracket \mathrm{SG} \text { book } \rrbracket=\{\mathrm{a}, \mathrm{b}, \mathrm{c}\} \\
\text { b. } & \llbracket \mathrm{PL} \text { book } \rrbracket=\{\mathrm{a}, \mathrm{b}, \mathrm{c}\}
\end{array}
$$

In choosing between the use of SG or PL with semantically-singular properties, we see that the two options are denotationally equivalent. The one-ness presupposition of SG is met by the semantically-singular property: every member has cardinality 1 . Without any constraints on its use, PL likewise readily composes with a semantically-singular property. The \# head, either SG or PL, serves as an identity map on the property, returning the same set of individuals taken as an argument. But Maximize Presupposition necessitates the use of the lexical item with the strongest presuppositions (that are met). Because SG carries stronger presuppositions-PL has none at all-with semantically-singular properties, we must use sG. It is only when SG's one-ness presupposition is not satisfied (i.e., when we have a semanticallyplural property containing individuals with cardinality greater than 1) that PL is used. In this way, morphological number corresponds directly to semantic number: the only licit combinations are SG with semantically-singular properties and PL with semantically-plural properties. 
Next, consider how numerals fit into this program of number marking. Suppose for now that cardinal numerals are restrictive modifiers: they compose with predicates and restrict the predicates' denotation to those elements with the appropriate cardinality. ${ }^{7}$

$$
\begin{array}{ll}
\text { a. } & \llbracket \text { one } \rrbracket_{\langle e t, e t\rangle}=\lambda \mathrm{P} \lambda \mathrm{x} . \mathrm{P}(\mathrm{x}) \wedge \mu_{\mathrm{CARD}}(\mathrm{x})=1 \\
\text { b. } & \llbracket \text { two } \rrbracket_{\langle e t, e t\rangle}=\lambda \mathrm{P} \lambda \mathrm{x} . \mathrm{P}(\mathrm{x}) \wedge \mu_{\mathrm{CARD}}(\mathrm{x})=2
\end{array}
$$

Assume further that numerals project between the noun and the \# projection: \# > numeral $>$ NP. I return to the motivation behind this structural assumption once the account gets extended to measure terms in Sect. 4 below.

The numeral one may compose with either a semantically-singular or a semantically-plural property; in either case, the resulting denotation is a set of atoms, each with cardinality 1 . This set of atoms satisfies the one-ness presupposition of SG, (17a): every member has cardinality 1 . Because the presupposition of SG is satisfied once one composes, Maximize Presupposition rules out the choice of PL, $(17 \mathrm{c}, \mathrm{d})$, and thus rules out one books. Again, composing restrictive one with either a semantically-singular or a semantically-plural property necessarily returns a set of individuals, each with cardinality 1 , a set that allows for the morphological singular form on the basis of SG. Because SG may be used in the presence of one, it must be used.

If we want to rule out the composition of a semantically-plural property with singular morphology, as in (17b), we may appeal to a principle of economy, whereby the strings with and without * compete: because (17a) and (17b) are denotationally equivalent, and because $(17 \mathrm{~b})$ is more complex (it contains *), (17b) is uneconomical and cannot occur. ${ }^{8}$

$$
\begin{aligned}
& \text { One }+\mathrm{SG} \\
& \text { a. } \quad \boldsymbol{J} \llbracket \mathrm{SG} \text { one book } \rrbracket=\{\mathrm{a}, \mathrm{b}, \mathrm{c}\} \\
& \text { b. } \quad \boldsymbol{x} \llbracket \mathrm{SG} \text { one } * \mathrm{book} \rrbracket=\{\mathrm{a}, \mathrm{b}, \mathrm{c}\}, \text { but failure of economy principle } \\
& \text { c. } \quad \boldsymbol{x} \llbracket \mathrm{PL} \text { one book } \rrbracket=\text { failure to apply Maximize Presupposition } \\
& \text { d. } \quad \boldsymbol{x} \llbracket \mathrm{PL} \text { one } * \mathrm{book} \rrbracket=\text { failure to apply Maximize Presupposition }
\end{aligned}
$$

The numeral two, with its restrictive semantics in (16b), requires that the property with which it composes be semantically plural. When two composes with a semantically-singular property, it looks among a set of atoms for individuals with the appropriate cardinality and finds none; the result is the empty set. We must say, then, that necessarily denoting the empty set, as in $(18 \mathrm{~b}, \mathrm{~d})$, is deviant and thus ruled

\footnotetext{
7 For discussion of numerals as modifiers, see Link (1987), Verkuyl (1993), Carpenter (1995), Landman (2003), among others; these assumptions regarding numeral semantics are taken up again in Sect. 4.1.

${ }^{8}$ Note that we have no evidence suggesting that the combination of one with a semantically-plural property should be ruled out by our system: the strings [SG one book] and [sG one *book] will both spell out as one book and denote the same set of individuals.
} 
out. ${ }^{9}$ With semantically-plural properties, two readily composes and restricts the nominal's denotation to those individuals with cardinality 2 . The one-ness presupposition of SG fails on such a denotation because it is not the case that all members number 1, (18c). Because the presupposition of SG fails, we must use PL instead, thus two books as in (18a).

$$
\begin{array}{ll}
\text { Two } & +\mathrm{PL} \\
\text { a. } & \checkmark \llbracket \mathrm{PL} \text { two } * \text { book } \rrbracket=\{\mathrm{a}+\mathrm{b}, \mathrm{a}+\mathrm{c}, \mathrm{b}+\mathrm{c}\} \\
\text { b. } & \boldsymbol{x} \llbracket \mathrm{PL} \text { two book } \rrbracket=\varnothing \\
\text { c. } & \boldsymbol{x} \llbracket \mathrm{SG} \text { two } * \text { book } \rrbracket=\text { presupposition failure } \\
\text { d. } & \boldsymbol{x} \llbracket \mathrm{SG} \text { two book } \rrbracket=\varnothing
\end{array}
$$

At this point, the current account captures the same range of data from Sauerland (2003). ${ }^{10}$ However, the account also falls victim to the same pitfalls: by tying morphological number so closely to semantic number via the measure in cardinality, we have no hope of capturing the facts from measure terms or cross-linguistic patterns of number marking.

\section{Analysis}

In what follows, I revise the system of number marking in the presence of numerals from Sect. 3 so that it may handle both measure terms and the observed crosslinguistic variation. I start by adopting an analysis of numerals as referring expressions, where cardinal numerals are formed on the basis of the functional element CARD (Zabbal, 2005). Next, I align the semantics of measure terms with CARD and make clearer the assumptions concerning the measure relevant to the oneness presupposition of SG. Finally, I locate the parameter determining crosslinguistic variation in the selection of the measure relevant to the one-ness presupposition of SG. The resulting proposal attributes measurement and therefore counting not to numerals proper, but to a functional projection $\mathrm{M}$ (easure)P. In number-marking languages, $\mathbf{M}^{0}$ often goes unpronounced, silently relating a numeral with the predicate denoted by a noun.

\footnotetext{
9 Such a move should be familiar from work on the ungrammaticality that results from logical triviality (e.g., Gajewski, 2002).

10 An anonymous reviewer raises the worry that pronouns may pose a problem for the predicate-checking nature of \#'s semantics. If pronouns enter the structure as a referential element at the D level, but find their form on the basis of \#P, the \# head would be unable to check the one-ness of that element. The ultimate verdict with respect to the current proposal will depend on the structural assumptions made for pronouns-assumptions that are well beyond the scope of the current work.
} 


\subsection{Numerals}

We started with minimal assumptions about numerals: they are property modifiers, type $\langle e t, e t\rangle$, and they occupy a position intermediate between \# and NP. Now it comes time to fill in the details of these assumptions. First, concerning their structure, I assume that numerals occupy the specifier of a functional projection, NumP (e.g., Selkirk, 1977; Hurford, 1987; Gawron, 2002), and that NumP occurs hierarchically between NP and DP (Ritter, 1992): ${ }^{11}$

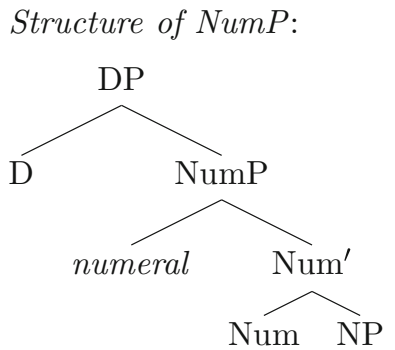

For their semantics, I take numerals to be individual-denoting expressions referring to natural numbers: numerals are of type $n$. The choice of $\mathrm{Num}^{0}$ determines the function of the numeral (e.g., cardinal, ordinal, etc.; Zabbal, 2005). Cardinal numerals are those that serve the purpose of counting; they are formed on the basis of the Num head CARD, which takes a predicate and returns a relation between numbers and individuals (in the spirit of Krifka, 1989). In (21), semantically-plural *boy composes with CARD and the numeral two. The result restricts the denotation of $*$ boy to just those (plural) individuals with cardinality 2 .

$$
\begin{aligned}
& \llbracket \mathrm{CARD} \rrbracket=\lambda \mathrm{P} \lambda \mathrm{n} \lambda \mathrm{x} . \mathrm{P}(\mathrm{x}) \wedge \mu_{\mathrm{CARD}}(\mathrm{x})=\mathrm{n} \\
& \llbracket \text { two CARD } * \text { boy } \rrbracket=\lambda \mathrm{x} .{ }^{*} \operatorname{boy}(\mathrm{x}) \wedge \mu_{\mathrm{CARD}}(\mathrm{x})=2
\end{aligned}
$$

We find independent support for this decompositional approach to cardinal numerals in languages with multiple numeral systems: one set of numerals that combines directly with nouns, and another set that must appear with classifiers. For example, Bale and Coon (2012) present data from two Mayan languages, Chol and Mi'gmaq, each with dual numeral systems. If we assume that one set of numerals behaves as those in English, incorporating a null classifier (i.e., CARD) that turns a number into a cardinal numeral, then we expect that set to compose directly with nouns without any overt classifier, as in (22). If there are numerals that have not incorporated the null classifier element, then we expect them to obligatorily occur with overt classifiers, as in (23).

\footnotetext{
${ }^{11}$ Locating NumP in the specifier of NP would work equally well. I have chosen to go the route in (19) in an attempt to reify the fact that Num takes NP as a semantic (and syntactic) argument. See Champollion (2010) and Scontras (2021) for discussion of the merits of parallel vs. right-branching structure for such constructions.
} 
Spanish-based numerals in Chol: classifier prohibited
a. *nuebe-p'ej tyumuty nine-CL egg
b. nuebe tyumuty
nine egg 'nine eggs'

(23) Mayan-based numerals in Chol: classifier required
a. cha'-p'ej tyumuty two-CL egg
b. * cha' tyumuty two egg

Such patterns are common: Greenberg (1972) notes that many languages fuse numerals and classifiers to form a single word, consistent with the analysis of cardinal numerals considered here, wherein the fused classifier would be an instance of CARD, and the resulting denotation incorporates the ability to count.

Note that CARD delivers the restrictive semantics for cardinal numerals that we assumed above: after composing with a predicate and a number $\mathrm{n}$, CARD restricts that predicate's denotation to just those members with cardinality $\mathrm{n}$. This restrictive semantics ensures that cardinals greater than one must compose with a semanticallyplural predicate (formed via *), as in (24b). Were such cardinals to compose with a semantically-singular (i.e., atomic) predicate, (24a), the result would be the empty set, $(24 \mathrm{c})$ : there are no individuals in the denotation of an atomic predicate with cardinality greater than 1 .

$$
\begin{aligned}
& \text { Assuming three boys: } \\
& \text { a. } \llbracket \text { boy } \rrbracket=\{a, b, c\} \\
& \text { b. } \llbracket * b o y \rrbracket=\{a, b, c, a+b, a+c, b+c, a+b+c\} \\
& \text { c. } \llbracket \text { two CARD boy } \rrbracket=\varnothing \\
& \text { d. } \llbracket \text { two CARD } * \text { boy } \rrbracket=\{a+b, a+c, b+c\}
\end{aligned}
$$

Next, recall the semantics given to the \# heads, repeated below, and consider how this semantics interacts with our revised assumptions concerning cardinal numerals. The full nominal structure, including both NumP and \#P, appears in (26). 
\#'s semantics:

a. $\llbracket \mathrm{SG} \rrbracket=\lambda \mathrm{P}: \forall \mathrm{x} \in \mathrm{P}[\mu(\mathrm{x})=1] . \mathrm{P}$

b. $\llbracket \mathrm{PL} \rrbracket=\lambda \mathrm{P} . \mathrm{P}$

Nominal structure:

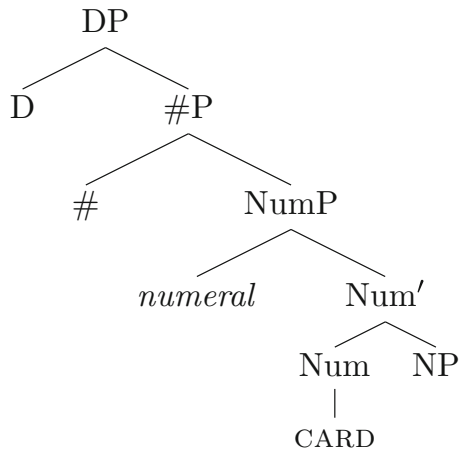

The \# head takes the nominal, NumP, as an argument. Here, I continue to assume that the measure relevant to the one-ness presupposition of SG is cardinality (note that cardinality is the measure supplied by the closest head to \#, CARD; more on this below). Number marking in the presence of numerals proceeds as it did above (cf. (17) and (18)):

Number marking with one:

a. $\quad \checkmark \llbracket$ SG one CARD book $\rrbracket=\{\mathrm{a}, \mathrm{b}, \mathrm{c}\}$

b. $\quad \boldsymbol{X} \llbracket \mathrm{SG}$ one $\mathrm{CARD}{ }^{*} \mathrm{book} \rrbracket=\{\mathrm{a}, \mathrm{b}, \mathrm{c}\}$, but failure of economy principle

c. $\quad \boldsymbol{X} \llbracket \mathrm{PL}$ one CARD book $\rrbracket=$ failure to apply Maximize Presupposition

d. $\quad \boldsymbol{x} \llbracket \mathrm{PL}$ one CARD ${ }^{*}$ book $\rrbracket=$ failure to apply Maximize Presupposition

(28) Number marking with two:

a. $\quad \boldsymbol{V} \llbracket \mathrm{PL}$ two CARD ${ }^{*}$ book $\rrbracket=\{\mathrm{a}+\mathrm{b}, \mathrm{a}+\mathrm{c}, \mathrm{b}+\mathrm{c}\}$

b. $\boldsymbol{x} \llbracket \mathrm{PL}$ two CARD book $\rrbracket=\varnothing$

c. $\quad \boldsymbol{x} \llbracket \mathrm{SG}$ two $\mathrm{CARD} * \mathrm{book} \rrbracket=$ presupposition failure

d. $\quad \boldsymbol{x} \llbracket$ SG two CARD book $\rrbracket=\varnothing$

Again, with cardinality determining number marking, one may compose with SG and therefore must, which results in singular morphology on the co-occurring nominal, as in (27a). Concretely, the presupposition of SG (the determinant of singular morphology) checks whether every member of the denotation of a nominal predicate evaluates to 1 with respect to the measure $\mu_{\text {card }}$. With two and other numerals greater than one, the presupposition of SG fails, so PL must be used instead. The result is plural morphology on the co-occurring nominal, as in (28a). In other words, we correctly derive one book and two books. ${ }^{12}$

\footnotetext{
$12 \mathrm{We}$ also derive plural marking with zero, as in zero books, assuming that nothing in

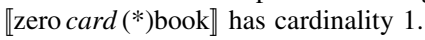


We thus maintain our coverage of basic nouns with numerals. Why, then, have we gone to the trouble of revising the assumptions concerning numerals? As we shall see in what follows, viewing numerals as referring expressions that serve as an argument of the functional counting element CARD allows for a straightforward account of number marking on measure terms.

\subsection{Measure terms}

Before applying this system of number marking to measure terms, we must settle on a semantics for these nouns. To that end, I begin with the observation that measure terms appear to have two distinct uses (Parsons, 1970). In the first, their ostensibly INTRANSITIVE use, measure terms compose with a numeral and reference an abstract measurement or extent. Intransitive measure terms typically occur as the objects of measure verbs (e.g., measure, weigh, etc.), as in (29a). They also appear in predicative be constructions, (29b), as well as modifiers of gradable adjectives, (29c), and in equative constructions, (29d).

Intransitive measure terms:

a. John weighs 100 kilos.

b. The temperature is 70 degrees.

c. John is two meters tall.

d. Ten degrees Fahrenheit is colder than ten degrees Celsius.

In (29a), the measure phrase 100 kilos specifies the extent of John's weight. Similarly, in (29c), two meters specifies the extent of John's height.

Intransitive uses of measure terms contrast with their TRANSITIVE uses, where an overt nominal argument-the substance noun-provides the material to be measured. The substance noun can be introduced via partitive, (30), or pseudopartitive constructions, (31). In what follows, I will focus on measure terms in pseudo-partitives, where the connection between the measure term and the substance noun is more direct (Selkirk, 1977).

Partitive:

a. I drank two liters of that wine.

b. I ate two kilos of those apples.

(31) Pseudo-partitive:

a. I drank two liters of wine.

b. I ate two kilos of apples. 
In (31), the measure terms serve to quantize the denotations of the substance noun: the measure phrase uses the specified extent familiar from intransitive uses to restrict the denotation of the nominal complement. ${ }^{13}$ For example, in (31b), two kilos of apples denotes a set of apple individuals: those pluralities of apples that measure two kilos.

Under this relational conception, in the intransitive use a measure term takes a numeral and returns the set of individuals that satisfy the relevant measure to the extent specified by the numeral. In this way, a measure phrase like 100 kilos will be true of an individual just in case it weighs 100 kilos: supply 100 as the numeral argument to the relation in (32) and the predicate of weighing 100 kilos results, as in (33).

$$
\begin{aligned}
& \llbracket \text { kilo }=\lambda \mathrm{n} \lambda \mathrm{x} . \mu_{k g}(\mathrm{x})=\mathrm{n} \\
& \llbracket 100 \text { kilos } \rrbracket=\lambda \mathrm{x} . \mu_{k g}(\mathrm{x})=100
\end{aligned}
$$

In their transitive uses, measure terms take an additional argument: the substance noun. Complements of transitive measure terms used in pseudo-partitive constructions must be bare plurals or mass nouns, suggesting that they refer at the kind level (Carlson, 1977; Chierchia, 1998). We may use the semantics for intransitive measure terms in (32) as the basis for the transitive measure term semantics, where the only difference is that the latter takes an additional kind-denoting internal argument supplied by the substance noun. ${ }^{14}$

$$
\begin{aligned}
& \llbracket \mathrm{kilo} \rrbracket=\lambda \mathrm{k} \lambda \mathrm{n} \lambda \mathrm{x} .{ }^{\cup} \mathrm{k}(\mathrm{x}) \wedge \mu_{k g}(\mathrm{x})=\mathrm{n} \\
& \llbracket \mathrm{CARD} \rrbracket=\lambda \mathrm{P} \lambda \mathrm{n} \lambda \mathrm{x} . \mathrm{P}(\mathrm{x}) \wedge \mu_{\mathrm{CARD}}(\mathrm{x})=\mathrm{n}
\end{aligned}
$$$$
\langle k,\langle n,\langle e, t\rangle\rangle\rangle
$$$$
\langle\langle e, t\rangle,\langle n,\langle e, t\rangle\rangle\rangle
$$

It bears noting that the semantic type given here for transitive measure terms resembles that given to the Num head CARD. The difference is that where CARD takes a predicate-denoting argument (it may compose with singular count nous), measure terms require a kind. The parallels in structure are obvious: CARD takes a predicatedenoting argument and then a numeral, forming NumP. A measure term (e.g., kilo) takes a kind-denoting argument and then a numeral, forming $\mathrm{M}$ (easure) $\mathrm{P}$. The relevant structures appear in (36) and (37) (see Scontras, 2021, and the references therein for a fuller discussion of these structural decisions). ${ }^{15}$

\footnotetext{
13 Strictly speaking, the measure term restricts the denotation of the predicate counterpart of the kind named by the substance noun. I return to the role of kinds in pseudo-partitives presently.

14 See Scontras (2014) for a detailed discussion of the relationship between transitive and intransitive uses of measure terms, where it is claimed that the transitive semantics of measure terms is prior and the intransitive semantics arises via existential closure of the kind argument.

15 For now, the substance noun in the measure structure in (37) is labeled as $n \mathrm{P}$. The label is meant to indicate only that the substance noun is kind-denoting and expresses morphological number, but likely does not project a full DP.
} 
(36) Cardinal numeral structure:

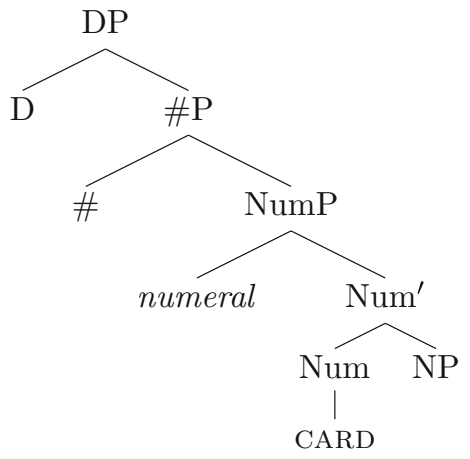

(37) Measure term structure:

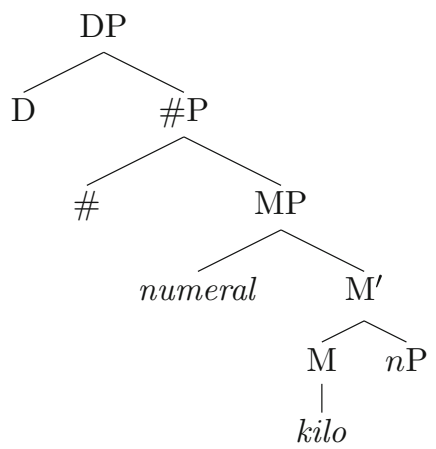

Given the similarities between CARD and measure terms like kilo, the following innovation suggests itself: align CARD with measure terms, such that both instantiate the category M. This move requires us to conceive of MP more broadly, taking it to be a measure phrase measuring either atoms (as in the case of CARD) or something more abstract (as in the case of kilo). In both cases, the measure is specified by the head of the measure phrase. 


\section{Generalizing MP:}

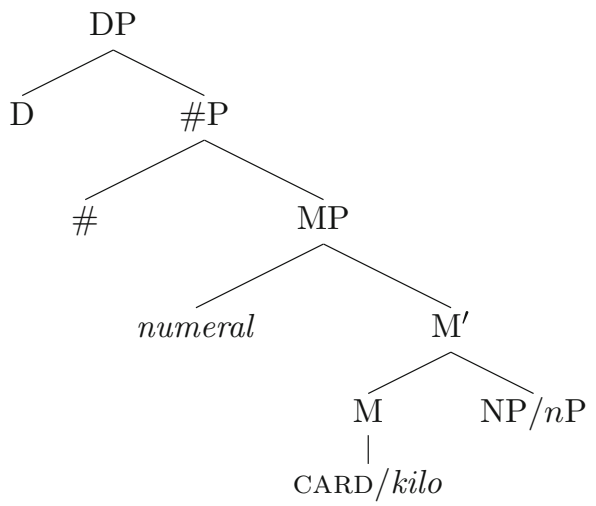

This move allows for an account of number marking on measure terms. To see how, first recall the challenge. As in the case of CARD, MP headed by a measure term denotes a nominal predicate, which may then be checked against the one-ness presupposition of SG. In (39), we have the denotation of one kilo of apples.

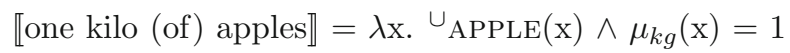

Like one boy, one kilo of apples denotes a set of individuals. The measure term kilo constrains the denotation of apples on the basis of the kilo measure, $\mu_{k g}$. One kilo of apples thus denotes the set of apple individuals measuring 1 kilo. However, the average apple weighs approximately 0.2 kilos, so in most scenarios the individuals denoted by one kilo of apples will be pluralities, or sums of individuals. In other words, the individuals denoted by one kilo of apples will not have cardinality 1. Checking such a set against the one-ness presupposition of SG relativized to $\mu_{\text {card }}$ therefore fails, and so we incorrectly predict plural morphology on kilo in (39): one kilos of apples.

Note that Sauerland's (2003) original referent-based system does not fare any better: $\phi$ occurs as the sister to DP, and absolute atomicity of the individual denoted by DP determines number morphology. However, in one kilo of apples vs. two+ kilos of apples, the referent is a quantity of apples and yet the number of apples measuring 1 or $2+$ kilos is irrelevant to the number morphology expressed on kilo. Number marking on measure terms is determined instead by the value of the numeral present: only with one do we have singular morphology.

For our system of number marking to handle both basic nouns and measure terms, the one-ness presupposition of English's SG cannot be invariantly tied to cardinality (and through cardinality to semantic number). However, recall that cardinality does yield the correct pattern of number marking in the case of cardinal numerals: in one boy, but not two boys, every individual referenced has cardinality 1 , so we get singular morphology on the noun. Note also that the cardinality 
measure, $\mu_{\text {card }}$, comes specified by CARD in the presence of a cardinal numeral: CARD occupies $\mathbf{M}^{0}$, the head closest to \# (cf. the structure in (38)).

Here is the initial claim: in English, the measure specified by the head of \#'s sister determines the measure $\mu$ relevant to the one-ness presupposition of SG.

$$
\begin{aligned}
& \text { \#'s semantics: } \\
& \text { a. } \llbracket \mathrm{SG} \rrbracket=\lambda \mathrm{P}: \forall \mathrm{x} \in \mathrm{P}[\mu(\mathrm{x})=1] . \mathrm{P} \\
& \text { b. } \llbracket \mathrm{PL} \rrbracket=\lambda \mathrm{P} . \mathrm{P}
\end{aligned}
$$

With cardinal numerals, CARD is the closest head to \# and so the measure relevant to the one-ness presupposition of SG is cardinality, $\mu_{\text {card }}$. Because SG checks for oneness on the basis of cardinality in the presence of cardinal numerals, the singular/plural distinction on basic nouns like book is sensitive to the semantic number of the predicate in question: when the predicate is closed under sumformation and contains pluralities in its denotation, it no longer satisfies the oneness presupposition of SG and so PL must be used. The result is plural morphology with semantically-plural predicates (i.e., those that include plural individuals formed via sum). Only when the predicate is semantically singular will the one-ness presupposition of SG be met on the basis of cardinality. We thus maintain our coverage of number marking on basic nouns, preserving the intuition that singular morphology indexes reference to atoms and plural morphology indexes reference to pluralities. Furthermore, we correctly predict singular morphology on basic nouns only with the numeral one.

Like CARD, measure terms occupy the head of \#'s sister. Also like CARD, measure terms supply a measure: $\mu_{k g}$ in the case of kilo, $\mu_{o z}$ in the case of ounce, etc. Assuming that the measure in the one-ness presupposition of SG is supplied by the closest head, measure terms both specify the relevant measure for which one-ness must be satisfied (e.g., $\mu_{k g}, \mu_{o z}, \mu_{l b}$, etc.) and have number morphology expressed on them (e.g., kilo vs. kilos). With the measure term kilo heading MP, $\mathrm{M}^{0}$ comes specified for the kilogram measure, $\mu_{k g}$. In (39), every member of the set denoted by one kilo of apples necessarily evaluates to 1 with respect to the kilo measure. With a different numeral, say two, no longer does every member measure 1 kilo; in fact, no member does. This pattern is precisely the pattern of number marking on English measure terms. To repeat: the measure supplied by the measure term-and not absolute cardinality-determines nominal number morphology. In the presence of numerals, singular morphology is checked against the measure specified by the head closest to \#. When those numerals are cardinals, the head is CARD and $\mu_{\text {card }}$ determines singular morphology. When those numerals are arguments of measure terms, the specific measure named by the term itself determines singular morphology. Crucially, when the numeral is one, everything in the denotation of \#'s sister will necessarily measure 1 with respect to the measure supplied by $\mathbf{M}^{0}$, allowing for singular morphology. When the numeral is something other than one, nothing in the sister of \# will measure 1 with respect to the measure supplied by the term, so PL must be used. 
While our focus is on the semantics of number morphology, a note on the morphosyntax of agreement is in order. In the proposed system, the head of \#P introduces the relevant number features. These features enter into agreement to determine the morphological form of nominal elements; with both numerals and measure terms, number morphology surfaces on the nearest overt head of the nominal construction: $\mathrm{N}$ in the presence of MP headed by silent CARD, and M with overt measure terms like kilo. The number features also enter into subject-verb agreement.

To summarize, we have seen that the measure relevant to the one-ness presupposition of SG is underspecified, and that in English this measure is supplied by the head closest to \#. In the case of cardinal numerals, cardinality determines number morphology: CARD is the head of \#'s sister and CARD measures cardinality. In the case of measure terms, the specific measure supplied by the given term determines number morphology. With kilo, everything in MP must measure 1 kilo in order for the one-ness presupposition of SG to be satisfied; only when the numeral one appears with kilo does this state of affairs hold. In this way, we account for number marking on measure terms in the presence of numerals, which, as we have seen, is sensitive to the numeral present and not to the number of individuals referenced.

The system as it stands yields the desired patterns, but it faces the problem of not being compositional: some sort of pragmatic magic looks into the semantics of the measure heads and plugs the relevant measure into the one-ness presupposition of SG. Can we do any better? In order to compositionally attribute the measure internal to $\mathrm{M}^{0}$ to the one-ness presupposition of $\mathrm{SG}$, we must consider what all of these measures have in common; we can then attempt to hang the system of English number marking on this property of measures.

MP will always denote a property that is quantity-uniform with respect to the measure internal to the semantics of $\mathbf{M}^{0}$. In other words, every individual in the denotation of MP will evaluate to the same extent with respect to this measure. (41) provides a formal definition of this notion of quantity-uniformity.

$$
\begin{aligned}
& \text { Quantity-uniform property: } \\
& \mathrm{QU}_{\mu}(\mathrm{P})=1 \text { iff } \forall \mathrm{x} \forall \mathrm{y}[\mathrm{P}(\mathrm{x}) \wedge \mathrm{P}(\mathrm{y}) \rightarrow \mu(\mathrm{x})=\mu(\mathrm{y})]
\end{aligned}
$$

Take, for example, the MP one boy. Assuming three boys, we get the denotation in (42).

$$
\llbracket \text { one CARD boy } \rrbracket=\{\mathrm{a}, \mathrm{b}, \mathrm{c}\}
$$

In (42), CARD heads MP, and internal to CARD is the cardinality measure $\mu_{\text {card }}$. The predicate one boy denotes a set of singular boys. When measured by $\mu_{\text {card }}$, every member returns the same value, namely 1 . With one kilo of apples, kilo heads MP and supplies the kilo measure $\mu_{k g}$; the predicate denotes a set of apple individuals 
that each return the same value when measured by $\mu_{k g}, 1$. The reader can verify that any measure supplied by $\mathrm{M}^{0}$ behaves similarly. Given that the aim is to tie the oneness presupposition to the measures in $\mathbf{M}^{0}$, we could try relativizing this presupposition to just those measures that determine quantity-uniform properties, as in (43a).

$$
\begin{aligned}
& \text { English \# heads: } \\
& \text { a. } \llbracket \mathrm{SG} \rrbracket=\lambda \mathrm{P}: \forall \mu \forall \mathrm{x} \in \mathrm{P}\left[\mathrm{QU}_{\mu}(\mathrm{P}) \rightarrow \mu(\mathrm{x})=1\right] . \mathrm{P} \\
& \text { b. } \llbracket \mathrm{PL} \rrbracket=\lambda \mathrm{P} . \mathrm{P}
\end{aligned}
$$

What results is a compositional account of English number marking: with cardinal numerals, number marking is sensitive to the quantity-uniform measure $\mu_{\text {card }}$, that is, to the semantic number of nominal predicates. With measure terms, number marking is sensitive to the quantity-uniform measure supplied by the measure term itself. There remains one serious worry, however: what happens in cases where there are multiple quantity-uniform measures that deliver conflicting results with respect to the one-ness presupposition of SG? I have in mind a (bizarre) scenario where, say, apples uniformly weigh half a kilogram. In this scenario, one kilo of apples would characterize a set of apple individuals that all evaluate to 1 with respect to $\mu_{k g}$, thus making the measure quantity-uniform and also satisfying the one-ness presupposition. However, in this scenario each apple individual will evaluate to 2 with respect to $\mu_{\text {card }}$, making that measure quantity-uniform but failing the one-ness presupposition. The compositional system of relevant measures we are considering would erroneously predict one kilos of apples in such a scenario. In other words, this system would undergenerate morphologically-singular forms because the one-ness presupposition is too strong. We could try weakening the oneness presupposition so that, instead of checking every quantity-uniform measure, it merely checks for the existence of some quantity-uniform measure satisfying the presupposition. However, this move would lead to the overgeneration of singular forms. In the same apple scenario, two apples would characterize a set of apple individuals each evaluating to 2 with respect to $\mu_{\text {card }}$ (correctly failing the one-ness presupposition of SG), but each apple individual would consist of two half-kilogram apples, thereby evaluating to 1 with respect to $\mu_{k g}$ and leading to the use of sG.

It seems, then, that rigidly tying the system of English number marking to (all or any) quantity-uniform measures delivers wrong predictions in fringe scenarios with multiple, conflicting quantity-uniform measures. Where does that leave us? Recall the facts: in the presence of measure terms, the measure named by the term serves to determine the one-ness presupposition of SG; in the absence a measure term (i.e., with cardinal numerals or no numeral at all), the one-presupposition defaults to $\mu_{\text {card }}$. Perhaps this is all there is to the English system of number marking: unless a measure is introduced explicitly via an overt measure term, the measure relevant to the one-ness presupposition of SG is $\mu_{\text {card }}$. When a measure is introduced via a measure term, that measure becomes relevant by virtue of being mentioned. In the next section, we see how the assumptions about the measures relevant to the one- 
ness presupposition of SG may be extended to provide an account of the crosslinguistic variation in number marking discussed in Sect. 2.2.2.

\subsection{Cross-linguistic variation}

In addition to deriving the English pattern of number marking for both basic nouns and measure terms, we must also allow sufficient flexibility in the system so that it may account for the patterns in Turkish and Western Armenian. The approach will be to derive the Turkish facts in addition to the English facts, and then assume variation within Western Armenian such that it can employ either the English or the Turkish system.

Recall that in Turkish and languages like it all numerals require singular morphology, which necessitates SG in numeral-noun constructions. With numerals greater than 'one', we thus require SG in the presence of a semantically-plural predicate. Consider once again the structure of a nominal predicate modified by a cardinal numeral, as in $(44 c)$.

$$
\begin{array}{ll}
\text { a. } & \llbracket b o y \rrbracket=\{a, b, c\} \\
\text { b. } & \llbracket \text { boy } \rrbracket=\{a, b, c, a+b, a+c, b+c, a+b+c\} \\
\text { c. } & \llbracket \text { two CARD } * \text { boy } \rrbracket=\{a+b, a+c, b+c\}
\end{array}
$$

The combination of SG with the numeral-modified predicate in $(44 \mathrm{c})$ is problematic because of the way we have aligned semantic and morphological number: we must allow singular-marked nominals to receive a plural interpretation. As was the strategy in accounting for measure terms in the previous subsection, here we can again take advantage of the flexibility allowed in the selection of the measure $\mu$ in the one-ness presupposition of SG. In English, I claimed that $\mu$ can be supplied by the head closest to \#, but this need not be the case in all languages.

Given our semantics for CARD, cardinal numerals serve as restrictive modifiers: they return a subset of a noun's denotation populated by individuals with the appropriate cardinality. By ensuring that every element has the same cardinality, cardinal numerals quantize the members of the resulting denotation. Crucially, every member of a quantized predicate has no parts that are also members of that predicate; in other words, every member of a quantized predicate is a smallest member (Krifka, 1989).

Take two boys in (44c). This predicate is true of three (plural) individuals: $a+b$, $\mathrm{a}+\mathrm{c}$, and $\mathrm{b}+\mathrm{c}$. Each of these individuals has no parts which are also in the denotation of two boys. In this way, every member of the predicate two boys is a smallest member of the predicate two boys: every member is an atom relative to the predicate in question. This situation-quantized predicate denotations where every member is a smallest member-generalizes to any cardinal numeral. In Turkish, then, number marking appears to be sensitive not to absolute atomicity (evaluated by, for example, the cardinality measure $\mu_{\text {card }}$ ) but rather to relative atomicity: quantized predicates bear singular morphology. Here we need a notion of relative atomicity: counting as atomic not with respect to the entire domain, but rather with 
respect to a specific predicate (Krifka, 1989; Chierchia, 1998). These relative atoms, call them "P-atoms", are the smallest elements of P: those elements of P that have no other elements of $\mathrm{P}$ as parts. ${ }^{16}$

In Turkish, the measure relevant to the one-ness presupposition of sG should count the smallest elements, or relative atoms of nominal predicates. This measure, $\mu_{\mathrm{P}-\text { atom }}$, is defined in (45).

$$
\begin{aligned}
& \mu_{\mathrm{P}-\operatorname{atom}}(\mathrm{y}) \text { is defined only if } \mathrm{y} \in \mathrm{P} \text {; when defined } \\
& \mu_{\mathrm{P}-\operatorname{atom}}(\mathrm{y})=|\{\mathrm{x} \in \mathrm{P}: \mathrm{x} \leq \mathrm{y} \& \neg \exists \mathrm{z} \in \mathrm{P}[\mathrm{z}<\mathrm{x}]\}| \\
& \text { Turkish \# heads: } \\
& \text { a. } \llbracket \mathrm{SG} \rrbracket=\lambda \mathrm{P}: \forall \mathrm{x} \in \mathrm{P}\left[\mu_{\mathrm{P} \text {-atom }}(\mathrm{x})=1\right] . \mathrm{P} \\
& \text { b. } \llbracket \mathrm{PL} \rrbracket=\lambda \mathrm{P} . \mathrm{P} \\
& \llbracket \text { two CARD }{ }^{*} \text { boy } \rrbracket=\{\mathrm{a}+\mathrm{b}, \mathrm{a}+\mathrm{c}, \mathrm{b}+\mathrm{c}\}
\end{aligned}
$$

In the presence of cardinal numerals, \# composes with a predicate as in (47). Every member of this predicate has no proper parts that are themselves members of the predicate, therefore every member of this predicate measures $1 \mathrm{P}$-atom. Supposing $\mu_{\mathrm{P}-\text { atom }}$ to be the measure relevant to the \# heads in Turkish, sG may-and, by Maximize Presupposition, must-be used with (47). In fact, all numeral-noun combinations will have a quantized denotation wherein the elements share a common cardinality, so it will necessarily be the case that every member measures 1 P-atom. In other words, with $\mu_{\mathrm{P}-\text { atom }}$ as the measure relevant to SG's one-ness presupposition, we predict singular morphology with all numerals. This is the pattern in Turkish-like languages. ${ }^{17}$

One way to view the distinction between the Turkish and English patterns of number marking in the presence of numerals is as a difference in whether the oneness presupposition of SG is relativized to the complement of \# (i.e., MP; $\mu_{\mathrm{P}-\text { atom }}$ ) or to the head of its complement (i.e., $\mathrm{M}^{0}$ ). In Turkish, we find the former strategy: because numerals, crucially those greater than 'one', quantize the predicates that they modify into sets of relative atoms, the one-ness presupposition of SG relativized to $\mu_{\mathrm{P}-\text { atom }}$ will always be satisfied in the presence of a numeral. In English, we saw that the head of \#'s sister can supply the relevant measure: either cardinality in the case of cardinal numerals (supplied by CARD) or the specific measure supplied overtly by measure terms.

The present account makes a prediction about number morphology on measure terms in Turkish. Every member of a predicate like two kilos of apples will measure $1 \mathrm{P}$-atom. In order to measure more than $1 \mathrm{P}$-atom, an individual would have to measure two kilos and be a proper part of a different member of the predicate that

\footnotetext{
16 This notion of relative atomicity differs from that found in Rothstein (2010), where atoms are defined relative to a context and not to a predicate.

17 Note that the approach correctly predicts singular agreement with all numerals in Turkish even if semantic plurality in such languages is not mere sum-formation, *, but something stronger such as closure under sum less the atoms, ${ }^{\star}$ (cf. Link, 1983). For arguments in favor of this stricter approach to plurality in Turkish, see Bale et al. (2011a, 2011b); for arguments against this approach, see Renans et al. (2017).
} 
also measures two kilos. But this is impossible: the monotonicity of the kilogram measure ensures that anything weighing two kilos has no proper parts that weigh two kilos. We therefore expect singular morphology on measure terms like kilo with all numerals in Turkish, which is precisely what we find in (48).

$$
\begin{aligned}
& \text { Turkish measure phrases: } \\
& \text { a. elma-dan bir kilo(*-lar) } \\
& \text { apple-ABL one kilo-PL } \\
& \text { 'one kilo of apples' } \\
& \text { b. elma-dan iki kilo(*-lar) } \\
& \text { apple-ABL two kilo-PL } \\
& \text { 'two kilos of apples' }
\end{aligned}
$$

In Western Armenian, we find optionality between the English and Turkish systems: numerals greater than 'one' optionally combine with either singular- or pluralmarked nouns. To account for this optionality, I simply assume that each of the two strategies above (Turkish- vs. English-like) is available when selecting the measure relevant to SG's presupposition. When the Turkish strategy is pursued, one-ness is relativized to P-atoms and so singular-marked nominals appear with numerals greater than 'one'; when the English strategy is pursued, one-ness is sensitive to cardinality, and so we find plural-marked nominals with these numerals. For both Turkish and Western Armenian, as with English, in the absence of numerals only semantically-singular nouns, (44a), appear with singular morphology, since semantically-plural nouns (i.e., predicates closed under sum-formation, (44b)) fail to meet the one-ness presupposition of $\mathrm{SG}$ - whether the presupposition is relativized to $\mathrm{P}$-atoms or to cardinality.

Taking stock, we now have not only an account of number marking on basic nouns and measure terms in English, but also an account of the cross-linguistic variation observed in patterns of number marking. Crucially, both sets of phenomena receive an account once we assume variation in the measure relevant to the determination of singularity. The following section considers an extension of the current account to the nominal system more broadly, taking into account obligatory singular morphology on mass nouns.

\section{A note on mass nouns}

So far, we have considered the semantics of number morphology on basic nouns like book and measure terms like kilo. However, basic nouns and measure terms are not the only nominal elements that express number morphology. Here we take a closer look at mass nouns like water.

Chierchia (2010) identifies three properties of mass nouns that are ("tendentially") constant across languages. The first property Chierchia calls the "signature property" of mass nouns, namely their inability to compose directly with numerals. Compare the phrases in (49); unlike count nouns, mass nouns resist direct counting. 
a. three apples/hamburgers/grapes.

b. *three waters/silvers/oils

To count instances of the substance denoted by mass nouns, we make use of a quantizing noun as in (50). Note that even when a quantizing noun mediates counting, mass nouns never appear as morphologically plural.
a. three cups of water
b. three pounds of silver
c. three quantities of oil

Next, mass nouns track the language-independent substance/object contrast. When two objects, say two books, meet, the objects retain their identities; we are left with two books. When two quantities of some substance, say water, meet, a single quantity of that substance results. Moreover, substances are continuous: a portion of some quantity of water is still water, whereas a portion of a book is not necessarily a book. Infants are attuned to these properties of their environment (Spelke, 1991; Carey, 1992), and languages are too: substances are named by mass nouns. ${ }^{18}$

Lastly, the mass/count distinction is flexible. A canonical mass noun may admit count uses, as in (51) and (52). ${ }^{19}$ However, this flexibility is firmly (and illuminatingly) constrained. The interpretations of count uses of mass nouns fall into two categories: either some contextually-supplied partition quantizes or packages mass nouns into discrete and stable portions for counting, (51), or counting proceeds over subkinds of the substance named, $(52) .^{20}$

John ordered three waters.

$\hookrightarrow$ John ordered three glasses/bottles of water

a. The hospital has three bloods on hand.

$\hookrightarrow$ the hospital has three kinds of blood on hand

b. You will find ten beers on tap at the bar.

$\hookrightarrow$ you will find ten kinds of beer on tap at the bar

\footnotetext{
${ }^{18}$ It is important to delimit the scope of this claim: whereas substances are coded as mass, objects are not always coded as count (cf. fake mass nouns like furniture).

19 Conversely, count nouns admit mass uses, as in John ate a salad with apple in it or there is table all over the floor. I ignore count $\rightarrow$ mass shifts for present purposes, but see Pelletier (1975) for discussion of the Universal Grinder that handles these shifts.

${ }^{20}$ Note that this second shift, into subkinds, also applies to count nouns. For example, three dogs could be interpreted as referencing three kinds of dogs.
} 
In sum, mass nouns name substances which cannot be directly counted. They also preclude plural morphology. ${ }^{21}$ However, mass nouns may be coerced into count uses; when they are, they deliver either quantized (i.e., apportioned) or subkind interpretations and can appear morphologically plural. Now, how do these properties conspire to inform the semantics of number marking on mass nouns? It seems that we want to preclude mass nouns from composing with the PL \# head. However, in doing so, two options present themselves. Under the first, both SG and PL (i.e., the \# heads) require some form of atomicity that is incompatible with mass denotations; mass nouns do not project \#P. Under the second option, mass denotations are compatible with the one-ness presupposition of SG; mass nouns always occur with singular morphology. I will argue that, on balance, the second option better accords with the sorts of data we have been considering.

Consider the first option: mass nouns do not express plural morphology because \#P checks for atomicity and mass nouns are not (stably) atomic. For present purposes, any standard notion of atomicity will do; (53) offers one implementation, ensuring that a predicate counts as atomic just in case every individual it is true of either has cardinality 1 or has minimal parts with cardinality 1.

$$
\begin{aligned}
& \mathrm{AT}(\mathrm{P})=1 \text { iff } \forall \mathrm{x}\left[\mathrm{P}(\mathrm{x}) \rightarrow \mu_{\mathrm{CARD}}(x)=1 \vee \exists \mathrm{y}\left[\mathrm{P}(\mathrm{y}) \& \mathrm{y}<\mathrm{x} \& \mu_{\mathrm{CARD}}(y)\right.\right. \\
& =1 \& \neg \exists \mathrm{z}[\mathrm{P}(\mathrm{z}) \& \mathrm{z}<\mathrm{y}]]]
\end{aligned}
$$

With a requirement for atomicity on the \# heads, substance-denoting DPs would lack \#P altogether. In other words, mass nouns would not host any number morphology, including PL. While this move correctly rules out plural morphology on mass nouns, it will run afoul of the patterns of number marking on measure terms: this atomicity requirement would presumably still be active in the presence of measure terms, yet they appear with regular number morphology. Suppose that the substances named by mass nouns were incompatible with an atomicity requirement on number morphology. Those very same substances appear in the denotation of a nominal like three ounces of water. If we were to use atomicity to rule out number morphology on mass nouns, then this same constraint would rule out number morphology on measure terms appearing with substance nouns that are mass, contrary to the patterns that we have observed. It would seem that the first option is off the table if we want to keep our account of number marking on measure terms.

The second option rules out plural morphology on mass nouns without engaging with the thorny issue of atomicity. Recall that the proposed system of number marking decides number morphology via competition between SG and PL: when SG, which has a stronger meaning, can be used, it is; otherwise PL must be used. One

\footnotetext{
${ }^{21}$ The lack of plural marking on mass nouns is a relatively stable phenomenon cross-linguistically. However, a handful of languages do pluralize their mass nouns. Tsoulas (2006) observes that Modern Greek allows the pluralization of mass nouns, and Gillon (2010) observes the same for Innu-aimun. Crucially, mass noun pluralization in these languages retains the mass character of the interpretation; in other words, the meaning that results is not a packaged, count interpretation. However, pluralization of mass nouns does delimit a narrow range of possible meanings, for example signaling that a striking amount of the relevant substance gets referenced.
} 
way to preclude the appearance of plural morphology on mass nouns would be to ensure that mass nouns always satisfy the one-ness presupposition of SG. For mass nouns to always appear singular, every element in their denotation must evaluate to 1 with respect to the relevant measure $\mu$.

In the absence of a measure term that explicitly introduces a relevant measure, the one-ness presupposition of English SG gets evaluated with respect to cardinality, $\mu_{\text {card }}$. For basic count nouns, this move ensures that semantically-singular predicates appear with SG, while semantically-plural predicates appear with PL. We saw how this move correctly predicts the patterns of number marking on numeral-less basic count nouns: singular book references only individual books, while plural books includes sums in its reference.

Next, consider the denotation of a mass noun. We could follow the suggestion, attributed by Chierchia (2015) to G. Magri, of treating mass nouns as naming singleton properties. ${ }^{22}$ The result has mass nouns name the contextually-relevant totality of some substance. Under this singleton-property approach to mass noun semantics, a mass noun like water would receive the denotation in (54).

$$
\llbracket \text { water } \rrbracket=\lambda \mathrm{x} . \mathrm{x}=\bigcup \text { water }
$$

The mass noun water names the property of being the supremum of the water property, which is always a singleton. The trick lies in fixing the cardinality of a singleton mass property at 1 . In this way, the semantics in (54) will satisfy the oneness presupposition of SG: every member of the predicate measures 1 with respect to $\mu_{\text {card }}$ (it only has one member, which we stipulate to have a logically-fixed cardinality). To summarize the current option, in order to ensure singular morphology on mass nouns, we may take advantage of the cumulative nature of the substances that they so often name and mandate that their denotation is always a singleton containing the (relevant) totality of the substance, which has cardinality 1.

In the presence of measure terms, the picture looks different. Measure terms introduce their own relevant measures, so, as we saw above, the numeral cooccurring with the measure term will determine its number morphology. We thus correctly predict plural morphology on measure terms with numerals greater than one, even when they appear with substance nouns that are mass (e.g., two liters of water).

Finally, consider the predictions for a Turkish-like system that evaluates one-ness on the basis of $\mu_{\mathrm{P}-\mathrm{atom}}$. Bare mass nouns, as singleton properties, will denote predicates with a single member that is also a minimal element of the predicate. Thus, we correctly predict the pattern of number marking on bare mass nouns in a Turkish-like system: only singular morphology should appear.

To summarize, it appears that mass nouns can be included in the current account of number marking once they are treated as singleton properties whose totality evaluates to 1 with respect to $\mu_{\text {card }}$, thereby satisfying the one-ness presupposition of SG and thus enforcing singular morphology on mass nouns. As a note of caution, it is worth mentioning that these current musings are not intended to decide the issue of

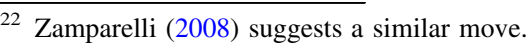


mass noun semantics, but rather to demonstrate possible directions in which to pursue an account.

\section{Conclusion}

We have considered data on number marking from three domains. First, we looked at basic nouns like book in English, whose morphological number depends solely on the semantic number of the nominal predicate. We also considered measure terms like kilo, assuming that these measure terms are nouns, at least to the extent that they should be handled by the same system that treats morphological number on basic nouns. Finally, we examined cross-linguistic variation in patterns of number marking, drawing on data from Turkish and Western Armenian.

The proposed account of these data relies on three assumptions: (i) cardinal numerals are formed on the basis of the functional element CARD, (ii) measure terms, like CARD, are relations between numbers and individuals, and (iii) morphological number is determined by the head of the functional projection \#P, which serves as an identity map on the predicate denoted by the nominal:

$$
\begin{array}{ll}
\text { a. } & \llbracket \mathrm{SG} \rrbracket=\lambda \mathrm{P}: \forall \mathrm{x} \in \mathrm{P}[\mu(\mathrm{x})=1] . \mathrm{P} \\
\text { b. } & \llbracket \mathrm{PL} \rrbracket=\lambda \mathrm{P} . \mathrm{P}
\end{array}
$$

The \# head SG carries with it a one-ness presupposition which ensures that every member of the nominal's denotation measure 1 with respect to some relevant measure $\mu$. In English-like languages, $\mu$ defaults to $\mu_{\text {card }}$ unless $\mu$ is supplied overtly by the head of the complement of \#. In this way, with basic nouns and cardinal numerals, cardinality determines morphological number. With measure terms, $\mu$ is supplied by the measure term itself; this accounts for why morphological number on these nouns is sensitive solely to the numeral present. We also saw how independent assumptions concerning the semantics of mass nouns could allow the proposed account to extend beyond basic nouns and measure terms.

Cross-linguistic variation in patterns of number marking falls out once we allow variation in the selection of $\mu$. In Turkish-like languages, where all numerals occur with singular-marked nouns, $\mu$ is relativized to the phrasal complement of \# on the basis of relative P-atoms. In other words, Turkish SG evaluates its one-ness presupposition on the basis of relative atomicity via the measure in P-atoms, with the definition repeated in (56).

$$
\begin{aligned}
& \mu_{\mathrm{P} \text {-atom }}(\mathrm{y}) \text { is defined only if } \mathrm{y} \in \mathrm{P} \text {; when defined: } \\
& \mu_{\mathrm{P} \text {-atom }}(\mathrm{y})=|\{\mathrm{x} \in \mathrm{P}: \mathrm{x} \leq \mathrm{y} \& \neg \exists \mathrm{z} \in \mathrm{P}[\mathrm{z}<\mathrm{x}]\}|
\end{aligned}
$$

Numeral-modified nominals are quantized such that every member of the predicate is a smallest member, so we correctly predict SG with all numerals when one-ness is tied to $\mu_{\mathrm{P}-\mathrm{atom}}$. In Western Armenian, where the pattern of number marking is 
intermediate between the English and the Turkish systems, there appears to be optionality in the selection of $\mu$ : either the English- or the Turkish-style approach may apply.

Taking stock, we have seen how a modified version of Sauerland's (2003) presuppositional approach to morphological number can handle variation in patterns of number marking - both cross-linguistic and within one and the same languageonce we assume flexibility in the selection of the measure relevant to the one-ness presupposition that determines morphologically-singular forms. In each case, the morphological singular requires elements of a predicate denotation to measure 1 . However, languages and constructions vary on what it takes to measure 1 for this purpose. Crucially, the proposed account of this variation makes do with a uniform syntax and semantics for nominals and numerals across the relevant languages (cf. the variation proposed by Bale et al., 2011a) within a standard semantics framework (cf. the OT account of Farkas and de Swart, 2010).

Work remains for a full vetting of the proposed system. The original data that motivated Sauerland (2003)_pronouns and conjunctions of proper names-still require an analysis. The precise mechanism yielding multiplicity inferences for plural morphology (i.e., plural $\Rightarrow$ more than one) is yet to be spelled out. Moreover, there are several specific predictions of the proposed semantics that should be explored. For example, if quantifiers compose with morphologically-singular nominals, then we may expect those nouns to be semantically singular, which could have implications for the semantics of quantification, as well as for cross-linguistic variation in quantifier semantics.

Acknowledgements For helpful feedback on earlier versions of this work, I am grateful to audiences at Sinn und Bedeutung, SALT, OSU, and Leibniz-ZAS. Thanks especially to Gennaro Chierchia and Luisa Martí for in-depth discussion of the puzzles and proposal. Finally, I thank Katrin Schulz and two anonymous reviewers for their comments and suggestions.

Open Access This article is licensed under a Creative Commons Attribution 4.0 International License, which permits use, sharing, adaptation, distribution and reproduction in any medium or format, as long as you give appropriate credit to the original author(s) and the source, provide a link to the Creative Commons licence, and indicate if changes were made. The images or other third party material in this article are included in the article's Creative Commons licence, unless indicated otherwise in a credit line to the material. If material is not included in the article's Creative Commons licence and your intended use is not permitted by statutory regulation or exceeds the permitted use, you will need to obtain permission directly from the copyright holder. To view a copy of this licence, visit http:// creativecommons.org/licenses/by/4.0/.

\section{References}

Bale, A., \& Coon, J. (2012). Classifiers are for numerals not for nouns: Evidence from Mi'gmaq and Chol. Talk presented at NELS 43, City University of New York.

Bale, A., Gagnon, M., \& Khanjian, H. (2011a). Cross-linguistic representations of numerals and number marking. Proceedings of SALT, 20, 79-95.

Bale, A., Gagnon, M., \& Khanjian, H. (2011b). On the relationship between morphological and semantic markedness: The case of plural morphology. Morphology, 21(2), 197-221. 
Carey, S. (1992). The origin and evolution of everyday concepts. In R. Giere (Ed.), Cognitive models of science (pp. 89-128). Minnesota, MN: University of Minnesota Press.

Carlson, G. (1977). Reference to kinds in English. Ph.D. thesis, University of Massachusetts at Amherst.

Carpenter, B. (1995). Distribution, collection and quantification: A type-logical account. In Lectures on type-logical semantics. Cambridge, MA: MIT Press.

Champollion, L. (2010). Parts of a whole: Distributivity as a bridge between aspect and measurement. Ph.D. thesis, University of Pennsylvania.

Chierchia, G. (1998). Reference to kinds across languages. Natural Language Semantics, 6, 339-405.

Chierchia, G. (2010). Mass nouns, vagueness and semantic variation. Synthese, 174, 99-149.

Chierchia, G. (2015). How universal is the mass/count distinction? Three grammars of counting. In A. Li, A. Simpson, \& W.-T. D. Tsai (Eds.), Chinese syntax in a cross-linguistic perspective (pp. 147-175). Oxford: Oxford University Press.

Farkas, D. F., \& de Swart, H. E. (2010). The semantics and pragmatics of plurals. Semantics and Pragmatics, 3, 1-54.

Gajewski, J. (2002). On analyticity in natural language. Ms., University of Connecticut.

Gawron, J. M. (2002). Two kinds of quantizers in DP. Paper presented at the LSA Annual Meeting.

Gillon, C. (2010). The mass/count distinction in Innu-aimun: Implications for the meaning of plurality. In B. Rogers \& A. Szakay (Eds.), Proceedings of WSCLA 15 (pp. 12-29). Vancouver: University of British Columbia.

Greenberg, J. (1972). Numeral classifiers and substantival number: Problems in the genesis of a linguistic type. Working Papers on Language Universals 9, 1-39. Reprinted in A. Makkai et al. (Eds.), Linguistics at the crossroads. Lake Buff, IL: Jupiter Press, 1977, 276-300.

Harbour, D. (2014). Paucity, abundance and the theory of number. Language, 90, 158-229.

Heim, I. (1991). Artikel und Definitheit. In A. von Stechow \& D. Wunderlich (Eds.), Semantik: Ein internationales Handbuch der zeitgenössischen Forschung (pp. 487-535). Berlin: de Gruyter.

Hurford, J. R. (1987). Language and number: The emergence of a cognitive system. Oxford: Blackwell.

Ivlieva, N. (2014). Multiplicity and non-monotonic environments. In U. Sauerland \& L. Crnič (Eds.), The art and craft of semantics: A festschrift for Irene Heim (pp. 245-251). Cambridge, MA: MITWPL.

Ivlieva, N., \& Sudo, Y. (2015). Another problem for alternative-based theories of plurality inferences: The case of mass plurals. Snippets, 29, 7-8.

Krifka, M. (1989). Nominal reference, temporal constitution and quantification in event semantics. In R. Bartsch, J. van Benthem, \& P. von Emde Boas (Eds.), Semantics and contextual expression (pp. 75-115). Dordrecht: Foris Publication.

Landman, F. (2003). Predicate-argument mismatches and the adjectival theory of indefinites. In M. Coene \& Y. D'hulst (Eds.), From NP to DP. Volume 1: The syntax and semantics of noun phrases (pp. 211-237). Amsterdam: John Benjamins.

Link, G. (1983). The logical analysis of plurals and mass terms. In R. Bäuerle, C. Schwarze, \& A. von Stechow (Eds.), Meaning, use, and interpretation of language (pp. 302-323). Berlin: de Gruyter.

Link, G. (1987). Generalized quantifiers and plurals. In P. Gärdenfors (Ed.), Generalized quantifiers (pp. 151-180). Dordrecht: D. Reidel.

Martí, L. (2020a). Dual number and the typology of the numeral-noun construction. Catalan Journal of Linguistics, 19, 159-198.

Martí, L. (2020b). Numerals and the theory of number. Semantics and Pragmatics, 13(3). https://doi.org/ $10.3765 / \mathrm{sp} .13 .3$.

Mayr, C. (2015). Plural definite NPs presuppose multiplicity via embedded exhaustification. Proceedings of SALT, 25, 204-224.

Parsons, T. (1970). An analysis of mass terms and amount terms. Foundations of Language, 6(3), 362-388.

Pelletier, F. J. (1975). Non-singular reference: Some preliminaries. Philosophia, 5(4), 451-465.

Renans, A., Tsoulas, G., Folli, R., Ketrez, N., Tieu, L., de Vries, H., \& Romoli, J. (2017). Turkish plural nouns are number-neutral: Experimental data. In A. Cremers, T. van der Gessel, \& F. Roeloefsen (Eds.), Proceedings of the 21st Amsterdam Colloquium (pp. 365-374). Amsterdam: ILLC.

Ritter, E. (1992). Cross-linguistic evidence for Number Phrase. Canadian Journal of Linguistics, 37, 197-218.

Rothstein, S. (2010). Counting and the mass/count distinction. Journal of Semantics, 27, 343-397.

Sauerland, U. (2003). A new semantics for number. Proceedings of SALT, 13, 258-275. 
Sauerland, U., Anderssen, J., \& Yatsushiro, K. (2005). The plural is semantically unmarked. In S. Kesper \& M. Reis (Eds.), Linguistic evidence: Empirical, theoretical and computational perspectives (pp. 413-434). Berlin: Mouton de Gruyter.

Sağ, Y. (2018). The semantics of Turkish numeral constructions. Proceedings of Sinn und Bedeutung, 22(2), 307-324. https://ojs.ub.uni-konstanz.de/sub/index.php/sub/article/view/108.

Scontras, G. (2013a). Accounting for counting: A unified semantics for measure terms and classifiers. Proceedings of SALT, 23, 549-569.

Scontras, G. (2013b). A unified semantics for number marking, numerals, and nominal structure. Proceedings of Sinn und Bedeutung, 17, 545-562. https://ojs.ub.uni-konstanz.de/sub/index.php/sub/ article/view/360.

Scontras, G. (2014). The semantics of measurement. Ph.D. thesis, Harvard University.

Scontras, G. (2021). Measure phrases. In D. Gutzmann, L. Matthewson, C. Meier, H. Rullmann, \& T. E. Zimmermann (Eds.), The Wiley Blackwell companion to semantics. New York: Wiley.

Selkirk, E. (1977). Some remarks on noun phrase structure. In P. W. Culicover, T. Wasow, \& A. Akmajian (Eds.), Formal syntax (pp. 285-316). New York: Academic Press.

Sigler, M. (1996). Specificity and agreement in Standard Western Armenian. Ph.D. thesis, Massachusetts Institute of Technology.

Spector, B. (2007). Aspects of the pragmatics of plural morphology: On higher-order implicatures. In U. Sauerland \& P. Stateva (Eds.), Presuppositions and implicatures in compositional semantics (pp. 243-281). New York: Palgrave-Macmillan.

Spelke, E. S. (1991). Physical knowledge in infancy: Reflections on Piaget's theory. In S. Carey \& R. Gelman (Eds.), Epigenesis of mind: Studies in biology and cognition (pp. 133-169). Hillsdale, NJ: Lawrence Erlbaum.

Tsoulas, G. (2006). Plurality of mass nouns and the grammar of number. Paper presented at GLOW 29. Verkuyl, H. J. (1993). A theory of aspectuality. Cambridge: Cambridge University Press.

Zabbal, Y. (2005). The syntax of numeral expressions. Ms., University of Massachusetts at Amherst.

Zamparelli, R. (2008). Bare predicate nominals in Romance languages. In H. Müller \& A. Klinge (Eds.), Essays on nominal determination (pp. 101-130). Amsterdam: John Benjamins.

Zweig, E. (2009). Number-neutral bare plurals and the multiplicity implicature. Linguistics and Philosophy, 32, 353-407.

Publisher's Note Springer Nature remains neutral with regard to jurisdictional claims in published maps and institutional affiliations. 